\title{
A Month of Data Collection in Vanuatu: From Scientific Work to Detective Work
}

\author{
Gaëlle Faivre $^{1 *}$, Jim Aimbie ${ }^{2}$, and Rodger Tomlinson ${ }^{1}$ \\ ${ }^{1}$ Griffith Centre for Coastal Management, Griffith University, \\ Gold Coast Campus, QLD, Australia \\ ${ }^{2}$ Department of Water Resources, Port Vila, Vanuatu
}

\begin{abstract}
INTRODUCTION
Griffith University in the Gold Coast, Queensland conducts research in the South Pacific Islands in the scope of an Eco-based Adaptation project. Most South Pacific island populations and infrastructure are located on the coast and have a lack of sufficient resilience to deal with the increasing incidence of natural disasters such as cyclones or tsunamis. Coastal erosion, flooding and water quality are among the biggest concerns of Small Island Developing States (SIDS) in the South Pacific. A lack of understanding of coastal processes can amplify coastal problems, increasing risks from natural hazards. In the South Pacific Islands, many coastal adaptations are being built without sufficient knowledge of coastal processes due to a lack of data collection or expertise resulting in the application of inappropriate solutions.
\end{abstract}

The study discussed in this paper is part of a Ph.D. research project led by Gaëlle, a student at the Griffith Centre for Coastal Management, aimed at improving our understanding of coastal processes within the lagoon system using modelling and data analysis. The case study is Erakor Lagoon in Vanuatu. The data collection was carried out during May 2019.

Organising data collection in Vanuatu from Australia is very challenging, particularly with limited resources and the many unplanned situations that can happen once in the field. In Vanuatu, all lands are private and authorization is required by the government and local chief to collect data. This story shows how situations can change rapidly and how community engagement is important when deploying instruments in the context of South Pacific Islands. Good lessons were learnt from this data campaign for organising future data collection in Vanuatu or other South Pacific Islands.

\section{Case Study}

\section{METHODS}

Erakor Lagoon in Efate Island, Vanuatu is located on the East side of Port Vila, capital of Vanuatu. Erakor lagoon consists of two lagoons: Ekasuvat lagoon (Lagoon 1) and Emtem lagoon (Lagoon 2) as shown in Figure 1 (Faivre et al., 2020).

The primary fieldwork involved deploying a wave buoy (spoondrift spotter) outside the reef and pressure sensors (RBR duets 16) over the reef to monitor wave transformation across the reef (Faivre et al., 2020). Four Marotte current meters and three salinity meters were also deployed to study the circulation within the lagoon and residence time for water quality purposes. They were attached at the bottom of the sea bed and fixed to a block of concrete (Figure 2a). Drifters were also deployed to measure surface currents using both Lagrangian and Eulerian methods. In addition, all the data were collated to calibrate a hydrodynamic model developed in Delft 3D.

DOI: 10.2112/JCR-SI101-078.1

*Corresponding author: g.faivre@griffith.edu.au

${ }^{\circ}$ Coastal Education and Research Foundation, Inc. 2020 


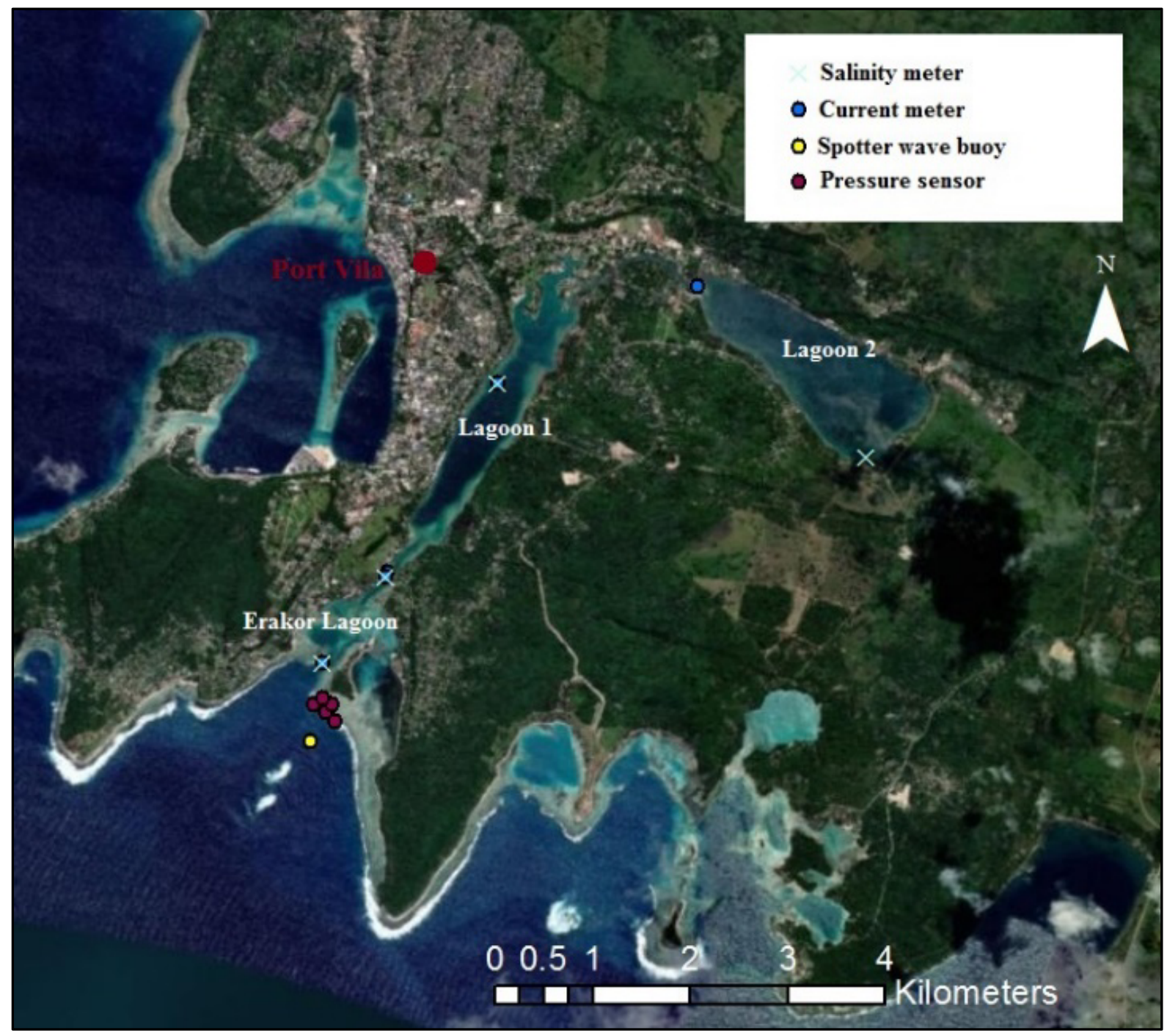

Figure 1. Location of deployed instruments within Erakor lagoon, Vanuatu. (Sources: Esri, DigitalGlobe, GeoEye, Earthstar Geographics, CNES/Airbus DS, USDA, AeroGRID, IGN, and the GIS User Community.)

\section{The Logistics}

First of all, as a Ph.D. student working in a remote area on a limited budget, logistics need to be made carefully. Before collecting any data, agreements with the government were signed and authorizations from local chiefs were given (usually involving gifts to thank them for the respect they expressed). The first few days of the data campaign were dedicated to preparing the fieldwork, introducing my research to the local communities and the Government and finding locals to help me in the field. I travelled on my own, but for safety reasons and University regulations, I needed to have a partner in the field with me. Jim Aimbie, an intern at the Water Department of Vanuatu, was able to assist me in the field during the entire data collection campaign and I also had assistance from students from the University of South Pacific.

We had to inform every local in the area that the campaign would last for a month to make sure that no one removed the instruments. Working with Jim, a local, was really helpful as he knew the community, the local traditions and also the Bislama, which is the national language of Vanuatu (Crowley, 2000). 


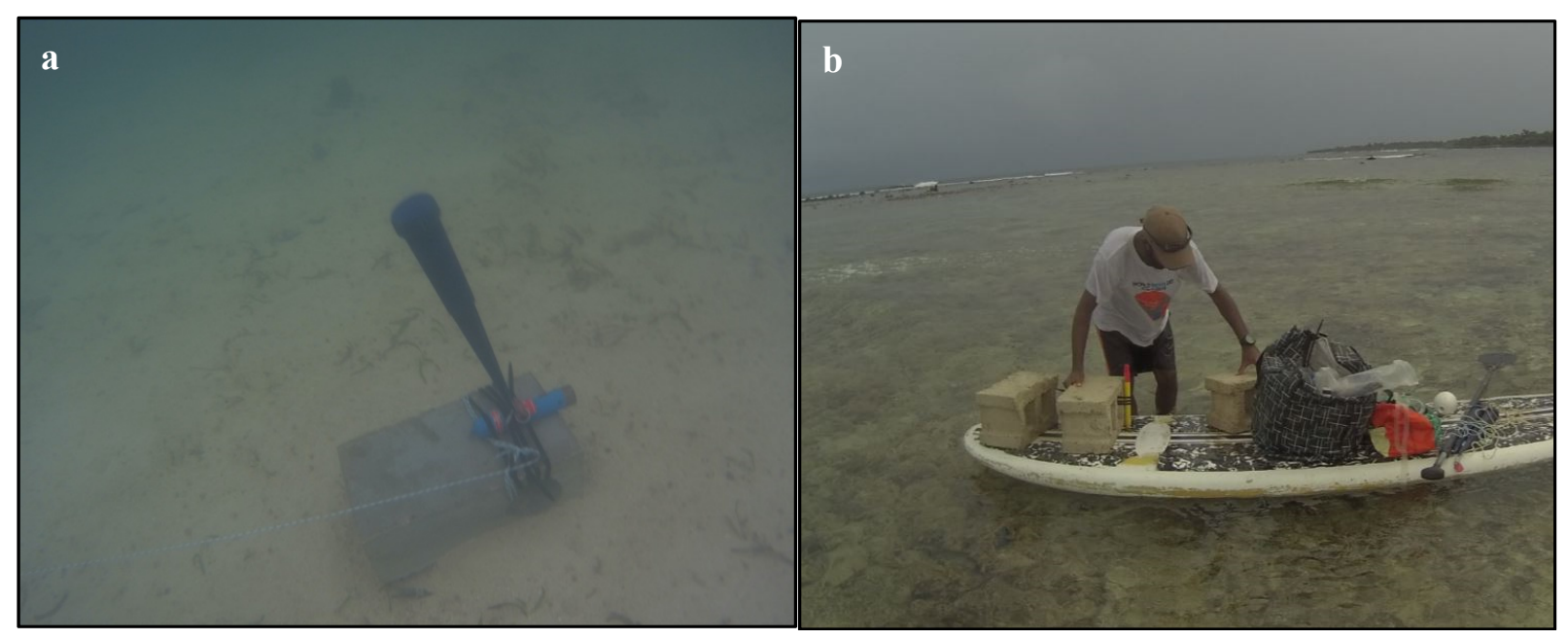

Figure 2. (a) Marotte current meter and salinity meter attached on a block at the bottom of the sea. (b) Jim installing an RBR on a block to be placed at the bottom of the sea bed and white float used to marked the location of the instrument. (Photos: G. Faivre.)

The plan was to deploy the spotter by boat and the rest of the instruments by paddle board (Figure 2b). A number of cement blocks were made with local home builders to act as heavy moorings and the Water Department assisted us with their truck for deploying the instruments. In Vanuatu, the majority of lands are private and accessing the lagoon at the desired location is often impossible. We therefore had to paddle from a resort to reach some locations with the instruments and blocks balanced on the paddle board, which was a very physical exercise. The paddle board was used extensively during the fieldwork to check on instruments and to deploy and move them within the lagoon. In addition, we conducted experiments with drifters and the paddle board was the easiest way to follow them, making sure no one removed them. The tide was an important factor to consider when we paddled. To optimize time, we tried to paddle in the same direction of the tide flow when possible.

\section{In the Field}

On May $7^{\text {th }} 2019$, with the help of the maritime office of Vanuatu and the University of South Pacific (USP) we deployed a spotter acting as a wave buoy for a month period to measure wave parameters. The mooring was made with a total of $60 \mathrm{~m}$ of rope using two surface floats to temporize wave effects and biofouling and two cements blocks of $25 \mathrm{~kg}$ each. Wave data parameters from the spotter and its location were available in real time online via a dashboard. The user was also notified if the spotter was outside its geofence (SofarOcean, 2020).

All the instruments were deployed as planned, marked by small white labelled floats to inform people the location of the instruments, and encourage them to not remove them. On the other hand, the floats could attract attention.

The first two weeks of data collection went well and as planned, we checked on the instruments regularly, until the spring tide came and things rapidly changed as some instruments became more accessible and the locals started to become curious. One morning, the white float marking the salinity meter and current meter in the lagoon 1 was missing. We decided to interview locals of this area and talk to the chief. When something happens, the chief knows. We printed ads of the missing instruments and passed it around detective style. We ended up talking from one person to another, which led to a community on the border of the lagoon who should have information. One kid said to other kids something in Bislama and I recognized they were talking about a blue instrument and I 
had not mentioned the color to him yet. The instruments were effectively blue. From this moment, I knew they had found the salinity meter. After reassuring them that we wouldn't tell the chief, we got it back. The current meter was still not found, however, even though the two instruments were attached together. We asked them where they found it and went with them to the location. The location was different to where we had deployed it and the block was on the side of the lagoon. This was unbelievable. The block was too heavy to have been removed by the tide and travel to this area. Someone must have removed it with a boat. Later the kid who removed the instrument came with us in the field and realized how hard work it was and they became very helpful with our research.

However, the game of hide and seek had only started. During this week, a few instruments went missing at different locations, but we ended up recovering all of them and redeployed them at their initial location. It was always a new detective story. Most of the time, the instrument was removed by curiosity and put back in place once discussed with the community. Eventually, no more issues happened and I knew instruments would not be touched anymore. I finally won the support and recognition of the community - I was so grateful!!!

The $29^{\text {th }}$ of May was the last day before recovering all the instruments. I checked the buoy via the dashboard and everything was in place. We planned the buoy recovery on the $30^{\text {th }}$ morning followed by all the instruments by boat.

At $6.30 \mathrm{am}$, we met with Jim and two other research assistants to recover the instruments, however when we arrived at the destination we had a problem! The spotter was missing!!! We divided the team in two, Jim and the other two assistants retrieved all the pressure sensors and current meters, while I had a mission to find the spotter. I checked the dashboard and saw that the buoy had moved outside the bay and toward the east following the coast (Figure 3).

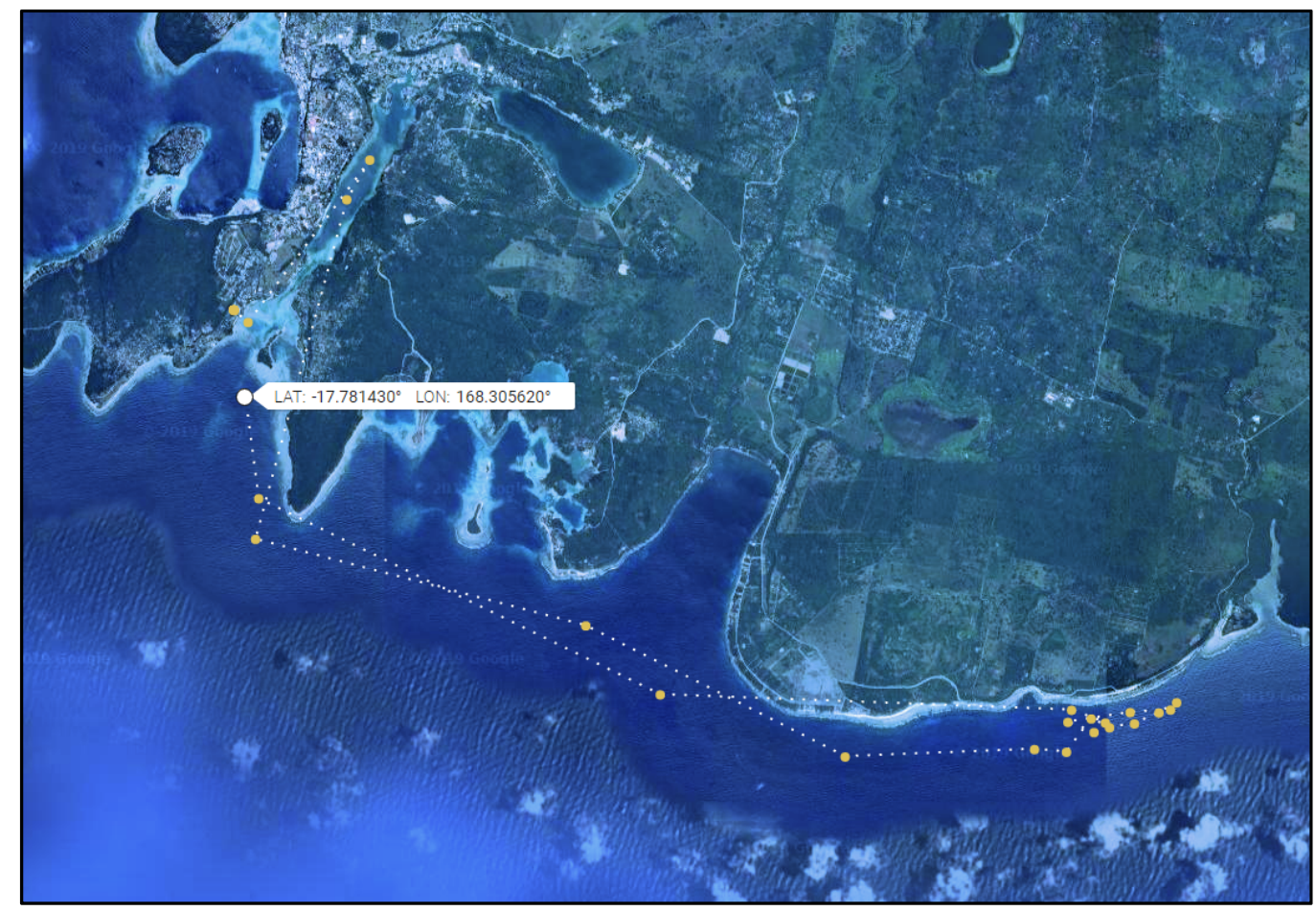

Figure 3. The wave spotter track shown in the Spotter Dashboard, in white is the position of the spotter moored and in yellow is the position during the spotter hunting. (Sources: Esri, DigitalGlobe, GeoEye, Earthstar Geographics, CNES/Airbus DS, USDA, AeroGRID, IGN, and the GIS User Community.) 
I could not believe that the mooring had failed - someone must have removed the spotter. The boat we had to recover the buoy with was not able to go outside the bay for security reasons and unfortunately, it was a public holiday so it was really hard to organize another boat. At one stage, the buoy was stationary in front of a resort (Figure 3).

My Airbnb host called the resort who confirmed that a boat with three persons aboard was there fishing. The Spotter was definitely kidnapped! The integrated GPS was very useful. The only problem was that the position was updated only every half an hour so they could have moved before we got to them. With the help of the Science Program Coordinator of the USP, Krishna Kotra, policemen and local residents, we followed the trajectory of the spotter, and went by car to the resort where the boat was moored. The aim was to find a local boat and recover the spotter. It was not a very easy task on a day off in this remote area. We managed to reach their location but by the time we arrived, the fishermen's boat was gone. This spotter hunting has lasted for 8 hours. In the end, we got it back in Erakor lagoon (Figure 4). It was a new case for the police officers who stayed with us during the whole day. Many persons were involved in the spotter being rescued. I would not have been able to get it back without them and the GPS updates.

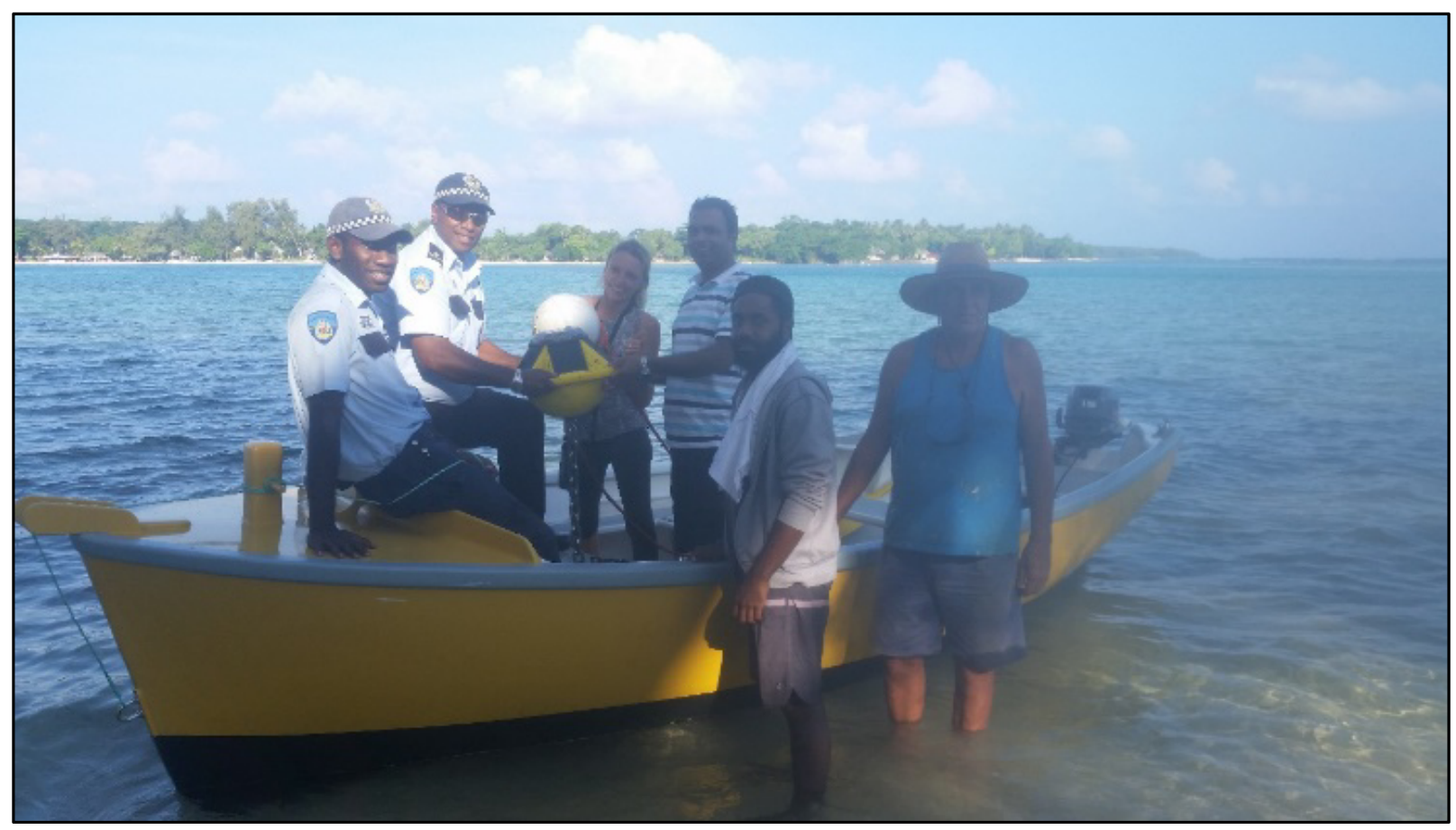

Figure 4. The Wave buoy (spotter) back after a long tracking day. (Photo: G. Faivre.)

\section{OUTPUTS}

Despite all the issues with missing equipment, the data was successfully used to calibrate and validate a hydrodynamic model (Faivre et al., 2020). Lessons learned from this fieldwork include how important it is to engage with the community and locals. This step should not be skipped. Sometimes, the curiosity of people can disrupt data collection, particularly in remote places where the use of marine instruments is not-well-known. It is a part of the fieldwork to inform the community but unfortunately, sometimes it is difficult to inform everyone

Fortunately, the community in Erakor is now aware of our research and instruments should be safe for any future deployments. 


\section{ACKNOWLEDGMENTS}

The authors are grateful to the Department of Water Resources of Vanuatu, the Office of the Maritime Regulator, and the University of South Pacific for supporting data collection in this study. Data collection was enabled by the support and involvement of the local communities and customary owners of the lagoons and associated land. This research was supported by a grant from a charitable organisation which neither seeks nor permits publicity for its efforts and under the approval of the research agreement between the cultural council and Griffith University.

The authors also thank the supervisors for their support conducting this research as well as the reviewers for their thoughtful comments and efforts towards improving our manuscript.

\section{LITERATURE CITED}

Crowley, T., 2000. The language Situation in Vanuatu. Current Issues in Language Planning, 1(1), 47-132.

Faivre, G.; Vieira da Silva, G.; Aimbie, J.; Ware, D.; Tomlinson, R.; Mackey, B., and Hong, Z., 2020. Coastal processes within a coral reef lagoon system: Erakor lagoon, Efate Island, Vanuatu. Journal of Coastal Research, Special Issue No. 95, pp. 1427-1432.

SofarOcean, 2020. Explore the Spotter Dashboard. https://www.sofarocean.com/products/spotter 